\title{
Development of a strategy to increase the efficiency of oil transportation through the pipeline
}

\author{
Igor Ivanov ${ }^{1, *}$, Ilona Avlasenko ${ }^{1}$ \\ ${ }^{1}$ Don State Technical University, Rostov-on-Don, Russian Federation
}

\begin{abstract}
This paper presents the authors' method of developing an original solution to improve the efficiency of oil transport through a pipeline based on the TRIZ-FSA (TIPS-FCA) system with obtaining a patent for a method and device.
\end{abstract}

\section{Introduction}

In our country in the nineties, the FSA (FCA) was effectively used in conjunction with TRZ (TSIP) (theory of solving inventive problems) in TRIZ-FSA (TIPS-FCA) systems to improve various technological processes. This paper describes the methodology for using the TRIZ-FSA (TIPS-FCA) system to develop a strategy for improving oil pipeline transport.

\section{Relevance}

At present, Russia is the world's largest producer of oil. In 2017 Russia produced 10.3 million barrels. per day, Saudi Arabia - 10 million barrels. per day, and the United States 9.4 million barrels. in a day. As a result, the main export commodity of our country is oil, and we get the main income from its sale. To increase the efficiency of implementation, it is necessary to increase the efficiency of its transportation. With the recent developments in the world of the oil industry, volumes of transportation of products that the organization can provide to the consumer market are growing.

The largest number of these products is intended for oil refining — the production of petroleum products, primarily various types of fuel (automobile, aviation, boiler, etc.) and raw materials for subsequent chemical processing. This factor increasingly makes us think about reducing the cost of transporting oil through the pipelines.

Statement of the problem.

How to increase the efficiency of oil transportation through the pipeline with minimal costs for the implementation of this project.

The theoretical part.

\footnotetext{
* Corresponding author: igoriv740@yandex.ru
} 


\section{Patent analysis.}

In this analysis, it is necessary to study the description of several patents related to this issue. Based on patent formulas, identify technologies that need to be changed in order to achieve a synergistic resulting effect. Identify original ways to change these technologies and based on them draw up your application for an invention.

Patent No. 1 [1].

Invention formula / Claim

A method of transporting highly viscous products by reducing viscosity by preheating and mixing with an inert gas, characterized in that the pressure on the product and inert gas lines is equalized, the product and inert gas are mixed until a gas-liquid mixture is formed, above the pour point of the product, and the amount inert gas support within $15-30 \%$ of the product volume.

Patent No. 2 [2].

Invention formula / Claim

Heated transport pipeline containing sections, shutoff valves, an external insulating layer and a heating element made up of separate sections and connected by ends to the mains, characterized in that each section of the electric heating element is located at the inlet of each section, is formed by a coil in the form of a coil with turns, tightly adjacent to each other and to the outer surface of the pipeline, and made providing a temperature of 8 15 degrees higher than the critical temperature of the film of boiling liquid in the pipeline to form a vapor film on the inner surface of the pipeline.

Patent No. 3 [3].

Invention formula / Claim

A method of transporting liquids through a pipeline, including pre-mixing with an inert gas and heating the mixture, characterized in that the liquid is mixed with inert gas until it is saturated, corresponding to the temperature and pressure of the liquid at the inlet to the pipeline, and the mixture is heated in sections of the pipeline located outside the local resistances, to a temperature of $10-40^{\circ}$ above the temperature of the liquid in each of these sections of the pipeline, which ensures the release of inert gas from the liquid with the formation of a gas boundary layer at the wall of the pipeline.

Analysis of patent information and determination of the conditions for solving the problem.

Of the three patents mentioned above, it is seen that in order to reduce the hydraulic resistance when pumping viscous oil products through a pipeline, they try to lower the viscosity of the product by preheating and supplying an inert gas to the system to form a gas boundary layer near the pipeline wall in order to reduce the friction resistance of the flow along the pipe surface.

The process of heating the pipeline is a complex and expensive operation, so we will not consider it.

We set a goal to supply an inert gas to the system using one device and ensure a decrease in the viscosity of oil throughout the pipeline without changing the design of the pipeline.

2. TRIZ (TIPS) Elements

To solve this problem, we will draw up technical contradictions:

TP (TC) -1

In order to reduce hydraulic resistance and energy consumption for transporting oil through the pipeline, it is necessary to reduce viscosity and supply inert gas to the system, but for this it is necessary to make a special heating system for the pipeline and a gas feed system, which is very difficult and expensive.

TP(TC) -2 
If only inert gas is supplied and a special system for heating the pipeline is not made, then the costs of re-equipping the system will be small, but at the same time, the hydraulic resistance and energy costs for transporting oil through the pipeline will change slightly.

We will take TP(TC) -1 as a basis, since it corresponds to the set goal.

Let us analyze methods for reducing viscosity without heating the pipeline.

Based on the analysis, the most effective method for dispersing hydrocarbon fuel was determined by treatment in UDD (universal disintegrator activator), which was used to obtain VTE and suspensions [4].

Development of a new strategy.

To achieve a synergistic effect, it is proposed to use Capstone microturbines as rotor drives, which have air bearings, due to which the shaft rotation speed of $96,000 \mathrm{rpm}$ is achieved and at the same time feed the exhaust gases of the microturbines into the system. As a result, not only the viscosity of oil is significantly reduced, but also new hydrocarbons with shorter chains are formed, which are easier to process into commercial fuels (proprietary technology) [5].

A diagram of the device for implementing the proposed technology is shown in Fig. 1.

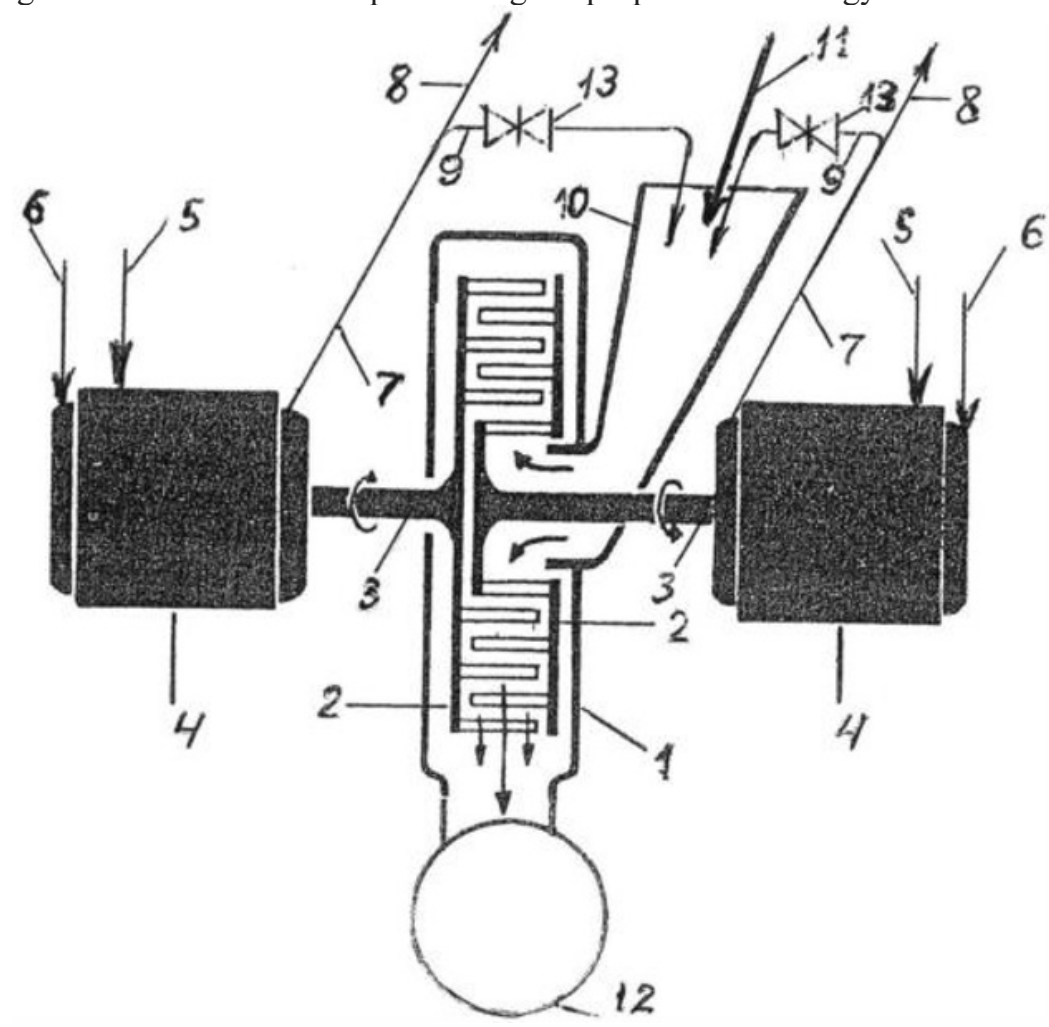

Fig. 1 A diagram of the device for implementing the proposed technology

The product 11, which must be transported through the pipeline using a pumping system, enters the mixing chamber of the disintegrator 10, where the exhaust gas flows 9. As a result, the product 11 is heated and partially mixed with the exhaust gases 9 .

Next, the product 11 and the exhaust gases 9 enter the inner part of the cage 1, where the product 11 and the exhaust gases 9 are processed by finger rotors 2 , which rotate in opposite directions at high speeds.

As a result, a nanotechnological process of molecular degradation occurs with a decrease in viscosity by a change in the composition of the product (when transporting oil, 
low-viscosity, higher-quality oil is formed). The exhaust gases 9 during the processing of the product 11 contribute to the intensification of the process and, standing on the surface of the stream, form a wall gas layer, which helps to reduce the unit cost of transporting the product through the pipeline.

Invention formula / Claim

1. A method of transporting products through a pipeline, including pre-mixing with an inert gas and heating the mixture, characterized in that before being fed into the pipeline, the mixture is processed in a disintegrator.

2. The method according to claim 1, characterized in that the mixture is heated with an inert gas, which uses the exhaust gases of gas turbine engines.

3. A device for implementing a method of transporting a product through a pipeline, containing a heating system for the product and a system for mixing it with inert gas, characterized in that a disintegrator is used as a system for heating the product and mixing it with inert gas, the wheels of which are connected to the power take-off shafts of gas turbine engines.

Calculation of the effectiveness of the proposed strategy

Initial data

Type of pumped liquid: oil

Productivity: 9 million tons /year

Pipeline length: $\mathrm{L}=440 \mathrm{~km}$

Definition of oil transportation work in year-A

$$
A=9000000 \mathrm{t} . * 440 \mathrm{~km} .=3960000000 \mathrm{tkm}
$$

The oil transportation tariff, depending on the conditions, is equal to (10-32) rub. / 100 tkm, while the cost of dispatching is 4.8 rubles / $100 \mathrm{tkm}$.

For calculation, we take the average tariff value of 15 rubles. / $100 \mathrm{tkm}$ and we believe that any changes in technology will not fundamentally affect the process of dispensation. The proposed technology on the oil transport process has 2 effects: 1 - mixing with an inert gas oil flow and 2-changing the properties of oil due to the degradation of molecules.

When mixed with an inert gas due to the low gas density compared to oil, gas is squeezed to the surface and a wall ring gas layer is created, which ensures a decrease in hydraulic resistance and energy consumption during transportation. Typically, in such technologies, energy costs are reduced by $15-30 \%$. For the reliability of the calculation, we accept $15 \%$.

When oil is subjected to disintegration processing, hydrocarbon molecules are degraded, which reduces viscosity and improves the composition of oil. Since this process has not yet been studied, we will take into account only a reduction in energy consumption due to a decrease in viscosity by $10 \%$.

As a result, total energy consumption will decrease by $25 \%$ and the overall effect of cost reduction per year will be:

$$
E_{i}=(15-4,8) / 100 * 3960000000 * 0,25=100,980,000.00 \text { RUBLES. }
$$

The effectiveness of the proposed technology implementation is determined based on the assessment of the investment project at the net present value of NPV, by which the value of the enterprise increases as a result of innovative investment according to the formula

$$
N P V=\sum_{i=0}^{n} \frac{E_{i}-E_{t}}{(1+k)^{i}}-I_{0},
$$

Ei - profit received in the $\mathrm{i}$-th period of time due to the implementation of this system.

$$
K \text {-discount } K=K_{1}+K_{2}+K_{3}
$$


K1 - the rate of return on invested funds, which can be achieved by investing in alternative publicly available commercial systems or simply in a bank with a set rate of return (bank interest rate on deposits) $\mathrm{K} 1=, 0.09$;

$\mathrm{K} 2$ - the inflation rate is 0.06 ;

$\mathrm{K} 3$ - the risk factor is 0.1 ;

$\mathrm{n}$ is the number of time periods during which funds will flow as a result of the implementation of the innovation project;

Io - originally invested.

Et - current expenses for the i-th time period include salary and all accruals.

We hire three employees to service the system installations with a salary of 50,000 RUBLES. All charges account for $43 \%$

$$
E_{t}=50000 \times 1,43 \times 3 \times 12=2,574,000.00 \text { RUBLES. }
$$

Since the effect of disintegration processing depends on the rotational speed of the rotors, we take Capstone microturbine as a drive, which has:

- high coefficient of performance (COP) for electricity from $26 \%$ to $33 \%$, total from $80 \%$ to $90 \%$ for power from $30 \mathrm{~kW}$ to $1000 \mathrm{~kW}$,

- low noise no higher than $60 \mathrm{~dB}$,

- full automation of work

- the use of air bearings, due to which the shaft rotation speed of $96,000 \mathrm{rpm}$ is achieved.

For the proposed technology, we take Capstone-S-65, with a capacity of $65 \mathrm{~kW}$, the cost of which at present in Russia in full complectation is 188,000.00 US dollars.

To determine the number of disintegrator installations, we determine the productivity A

$$
A=9000000 / 365 \times 24=1027,4 T / h .
$$

Currently, disintegrators are produced with a capacity of $0.5-20 \mathrm{~T} / \mathrm{h}$ driven by electric motors having $5000 \mathrm{rpm}$. As the initial data for the design we take $12 \mathrm{~T} /$ hour. Since the performance depends on the revolutions, when using a drive from a microturbine with $96,000 \mathrm{rpm}$. productivity will be $384 \mathrm{~T} /$ hour. Therefore, to ensure a total productivity of 1027.4 T / h. It will take 3 of these installations. Since the project is innovative and has no analogues, then we will take into account 4 installations ( 3 operating and 1 reserve). In addition, it is advisable to establish a storage tank and a room for units.

The cost of disintegrators manufactured in Russia with a drive from electric motors of various companies ranges from 200,000.00 rubles to 3,000,000.00 rubles.

For our project we will accept 3000000.00 RUBLES. The cost of the storage capacity is $7,500,000.00$ RUBLES. The cost of the premises is 3,200,000.00 RUBLES.

Totally - initially invested in the project will be:

$$
I o=8 \times 188000 \times 63+4 \times 3000000+7500000+3200000=117,452,000.00 R \text { RBLES. }
$$

The exchange rate taken 63rub. for 1 US dollar.

For 5 years of project implementation NPV $=147189.5$ thousand RUBLES. with a breakeven period of 1.6 years

Conclusion

The proposed innovation investment strategy based on the FSA (FCA) makes it possible to increase the efficiency of the entire system with minimal costs

The proposed example of the implementation of this strategy to improve the efficiency of oil transport through a $440 \mathrm{~km}$ pipeline shows that 5 years of project implementation $\mathrm{NPV}=147,189.50$ thousand RUBLES with a payback period of 1.6 years, which indicates great potential for its application in various fields of activity. 
The economic efficiency of this investment project, calculated by the NPV indicator for 5 years of project implementation is 77,944,954.00 RUBLES with a breakeven period of 6.8 months.

\section{Reference}

1. I.A. Ivanov, V South Russian forum "Power Efficiency Economy" (2010)

2. I.A. Ivanov "Patent for designing 2013147549. Application \# 2559055. Registered in Russian Federation roster on 10 July 2015

3. I.A. Ivanov, I.V. Avlasenko, E.V. Gatsenko, International scientific and technical journal, 2, (2018)

4. I.A. Ivanov, G.E. Persiyanova, Interagromasch (2018)

5. I.A. Ivanov, A.S. Zhuravlev, Interagromasch (2017)

6. A.S. Vasiliev, I.A. Ivanov, Interagromasch (2017)

7. I.A. Ivanov, L.M. Avlasenko, Interagromasch (2017)

8. I.A. Ivanov, G.E. Persiyanova, Interagromasch (2015)

9. I.A. Ivanov, A.N. Kuleshov, Alukhanyan, Publishing centre DSTU (2011)

10. The reported study was funded by RFBR according to the research project № 19-01000904 